\title{
Crescimento da cultura do girassol irrigado com diferentes tipos de água e adubação nitrogenada ${ }^{1}$
}

\author{
Cley A. S. de Freitas ${ }^{2}$, Alexandre R. A. da Silva ${ }^{3}$, Francisco M. L. Bezerra ${ }^{3}$, \\ Ricardo R. de Andrade ${ }^{3}$, Francisco S. B. Mota $^{4} \&$ Boanerges F. de Aquino $^{5}$
}

\section{RESU M O}

O bjetivou-se, com o presente trabalho, avaliar o crescimento vegetativo do girassol irrigado com diferentes lâminas de esgoto doméstico tratado e água de poço freático e adubado com diferentes doses de nitrogênio. 0 experimento foi conduzido no Centro de Pesquisa sobre Tratamento e Reúso de Águas Residuárias, em Aquiraz, CE. O delineamento estatístico adotado foi o de blocos ao acaso, no esquema de parcelas subsubdivididas, com quatro repetições. $N$ as parcelas foram avaliados os efeitos dos dois tipos de água de irrigação sobre os parâmetros de crescimento da cultura e, nas subparcelas, os efeitos das cinco lâminas de irrigação baseadas em percentuais da evaporação do tanque classe $A$ (ECA), que corresponderam à multiplicação da ECA pelos fatores 0,$25 ; 0,50 ; 0,75 ; 1,00$ e 1,$25 ;$ nas subsubparcelas determinou-se 0 efeito de quatro doses de adubação nitrogenada, a saber: $25,50,75$ e $100 \mathrm{~kg} \mathrm{ha}^{-1}$. A al tura da planta, diâmetro do caule e número de folhas, aumentaram linearmente em função das lâminas de irrigação. O s valores obtidos para água de reúso sempre foram superiores aos obtidos com a água de poço. O diâmetro do capítulo aumentou de modo quadrático em função do aumento da lâmina de irrigação e das doses de adubo nitrogenado.

Palavras-chave: Helianthus annuus L., esgoto tratado, gotejamento

\section{Growth of irrigated sunflower under different water sources and nitrogen fertilization}

\begin{abstract}
The objective of the present study was to evaluate the growth of sunflower crop irrigated with different water sources (both treated wastewater and well water) and application of different rates of nitrogen fertilizer. The experiment was conducted at the Research Center of Treatment and Reuse of Sewer W ater located in the municipality of Aquiraz in the State of Ceará, Brazil. The statistical design consisted of a randomized block in split-plots with four replications. In the plots, the effects of two types of irrigation water on sunflower growth parameters was evaluated and in the subplots the effects of the five irrigation levels; according to the percentage of Class A Evaporation Pan (ECA),corresponding to the multiplication of ECA by factors of $0.25,0.50,0.75,1.00$ and 1.25 levels were determined. In splitplots, the effects of the four rates of nitrogen $\left(25,50,75\right.$ and $\left.100 \mathrm{~kg} \mathrm{ha}^{-1}\right)$ on the same grow th parameters were evaluated. The plant height, stem diameter and number of leaves increased linearly as a function of the irrigation water levels. The parameter values obtained for wastewater were consistently higher than those obtained with well water. The capitulum diameter increased in a quadratic manner as a function of the irrigation water levels and nitrogen fertilizer rates.
\end{abstract}

Key words: Helianthus annuus L., treated wastewater, drip irrigation

\footnotetext{
${ }^{1}$ Extraído da Tese de Doutorado apresentada pelo primeiro autor ao Programa de Pós-Graduação em Engenharia Agrícola da U niversidade Federal do Ceará (UFC), Fortaleza, CE

2 Instituto Federal de Educação, Ciência e Tecnologia do Ceará, Campus Avançado de Tianguá, CEP 60115-282, Tianguá, CE. E-mail: anderson_agrotec@yahoo.com.br

${ }^{3}$ DEN A/UFC. Campus do Pici, Bloco 804, CEP 60455-760, Fortaleza, CE. E-mail: alexandre reuber@hotmail.com; mbezerra@ufc.br; rrandrade@hotmail.com

${ }^{4}$ DEHA/U FC. Campus do Pici, Bloco 713, CEP 60451-970, Fortaleza, CE. E-mail: suetonio@ufc.br

5 DCS/U FC. Campus do Pici, Bloco 807, CEP 60440-554, Fortaleza, CE. E-mail: aquino@ufc.br
} 


\section{INTRODUÇÃO}

O girassol (Helianthus annuus L.) responde por cerca de aproximadamente $13 \%$ de todo o óleo vegetal produzido mundialmente e ocupa posição de destaque entre as cinco maiores culturas produtoras de óleo vegetal comestível (Prado $\&$ Leal, 2006). Atualmente, esta cultura se inseriu entre as espécies vegetais de maior potencial para a produção de energia renovável no Brasil, sendo enquadrada como importante fornecedora de matéria-prima para a produção de bicombustíveis.

Trata-se de uma cultura pouco exigente em água, o que não significa que seu desenvolvimento será alterado com a deficiência hídrica dos solos. A água é fator limitante para a produção agrícola e a disponibilidade hídrica, sobretudo para a região semiárida, em que comumente se tem baixas e irregulares precipitações pluviométricas, a produção agrícola pode comprometer-se significativamente (Santos et al., 2009).

Pesquisas comprovam a importância da disponibilidade hídrica no desenvolvimento vegetativo do girassol, como a realizada por Silva et al. (2007), que observaram incremento significativo e linear da altura das plantas de girassol em função das lâminas de irrigação, com altura máxima da planta de $1,51 \mathrm{~m}$, obtida com a lâmina de irrigação de $522,1 \mathrm{~mm}$ por ciclo.

$\mathrm{O}$ nitrogênio, por desempenhar funções relevantes no metabolismo e na nutrição do girassol, tem sido objeto de vários estudos nos quais se objetiva averiguar a importância da adubação nitrogenada nas características morfológicas da cultura e seus eventuais reflexos na produtividade. Carelli et al. (1996) e Biscaro et al. (2008) comprovaram que o aumento da adubação nitrogenada proporciona incremento das variáveis vegetativas e produtivas do girassol.

Em esses fatores de produção, água e adubação nitrogenada, além de limitarem a produção agrícola carecem de um consenso a respeito dos níveis ótimos a serem aplicados, para se obter o máximo rendimento agronômico do girassol, que varia de acordo com a cultivar e com as condições ambientais uma vez que, assim como a falta, os excessos desses fatores de produção podem refletir no insucesso da cultura em condições de campo (Mousinho et al., 2003). Com isto, para se obter a maximização do rendimento agrícola, fazem-se necessários trabalhos interagindo referidos fatores de produção. Nesta perspectiva, várias pesquisas vêm se certificando da interação positiva entre a adubação nitrogenada e a disponibilidade hídrica no aumento da eficiência de produção das culturas, como Silva et al. (2008), para a cultura do alface americana e Barros et al. (2002) para a cultura do Melão.

Diante da escassez de água, seja pela qualidade e/ou quantidade, e o consumo excessivo de água pela irrigação que chega a ser de aproximadamente $70 \%$ da demanda total, atualmente, vem sendo disseminada a possibilidade de se utilizar águas residuárias para a produção agrícola. A adoção do reúso planejado de águas residuárias domésticas na agricultura irrigada, vem sendo considerada um prodigioso meio para abrandar a problemática da escassez hídrica no semiárido, sobremaneira nas áreas circunvizinhas às cidades (Sousa et al., 2006).
O uso da água de esgoto doméstico tratado para fins de irrigação ainda permite aumentar, mesmo indiretamente, a oferta de água destinada ao consumo humano. A redução dos impactos ambientais também é outro benefício atribuído ao reúso, visto que os nutrientes presentes na água de reúso (como o nitrogênio) quando lançados nos aquíferos, podem provocar severas contaminações ambientais. Assim, quando esta água é utilizada na irrigação das culturas agrícolas, o problema é minimizado e partes das exigências nutricionais das culturas podem ser supridas pelos nutrientes presentes na própria água de reúso, favorecendo a redução dos custos com fertilizantes químicos (Ramos, 2007; Cerqueira et al., 2008).

Souza et al. (2010) observaram, para as variáveis vegetativas altura da planta, diâmetro do caule e número de folhas do girassol irrigado com água de esgoto, os valores médios de $106,26 \mathrm{~cm} ; 9,41 \mathrm{~mm}$ e 19,33 folhas, respectivamente, constatando-se superioridade estatística, quando comparados aos valores médios obtidos com a irrigação com água de poço, que foram de $81 \mathrm{~cm} ; 6,23 \mathrm{~mm}$ e 15,33 folhas, respectivamente. Já Santos et al. (2010) não constataram, trabalhando com a cultura do gergelim sob dois tipos de água de irrigação (água de abastecimento e reúso) diferença significativa da altura de inserção do primeiro fruto em função do fator tipo de água de irrigação.

Embora haja várias vantagens inerentes ao uso da água de reúso na agricultura, Bastos et al. (2003) alertam para a possibilidade da existência de micro-organismos patogênicos na água de esgoto doméstico tratado e que sua utilização pode, de forma negligenciada, envolver sérios riscos à saúde humana. Desta maneira, a utilização da água de reúso para a produção de culturas destinadas a bicombustíveis e irrigadas por gotejamento, minimiza as possíveis contaminações humanas e contribui para a promoção de uma agricultura cada vez mais sustentável.

Face ao exposto, a pesquisa objetivou avaliar o desenvolvimento vegetativo do girassol, cultivar Multissol, irrigado com diferentes lâminas de esgoto doméstico tratado e água de poço freático, sob diferentes doses de nitrogênio.

\section{Material e MÉTOdos}

O experimento foi conduzido entre os meses novembro e fevereiro de 2009/2010, no Centro de Pesquisa sobre Tratamento e Reúso de Águas Residuárias, pertencente à Companhia de Águas e Esgotos do Ceará (CAGECE), localizado no município de Aquiraz, Região Metropolitana de Fortaleza. A área experimental encontra-se localizada ao sul da cidade de Aquiraz, com coordenadas locais de referência de $3^{\circ} 54^{\prime} 05^{\prime \prime}$ de latitude Sul e $38^{\circ} 23^{\prime} 28^{\prime \prime}$ de longitude a Oeste de Greenwich , a uma altitude média de 14,2 m.

O clima da região, segundo a classificação climática de Köppen, é AW', correspondente à Tropical chuvoso, com pequenas oscilações relacionadas ao regime pluviométrico, com precipitação média anual superior a $1.500 \mathrm{~mm}$. O solo da área pertence à classe dos Argissolos, textura arenosa e relevo plano (EMBRAPA, 2006). Os atributos físico-hídricos e químicos do solo da área experimental são apresentados nas Tabelas 1 e 2, respectivamente. 
Tabela 1. Atributos físico-hídricos do solo da área experimental

\begin{tabular}{lcc}
\hline \multicolumn{1}{c}{ Composição físico-hídrico } & \multicolumn{2}{c}{ Camada (m) } \\
Composição granulométrica $\left(\mathrm{kg} \mathrm{kg}^{-1}\right)$ & $0-0,20$ & $0,20-0,40$ \\
Areia grossa & 495 & 603 \\
Areia fina & 434 & 322 \\
Silte & 57 & 56 \\
Argila & 14 & 19 \\
Argila natural & 10 & 16 \\
Classificação textural & Areia & Areia \\
Densidade $\left(\mathrm{kg} \mathrm{dm}^{-3}\right)$ & & \\
Solo & 1,57 & 1,58 \\
Partículas & 2,62 & 2,62 \\
Umidade do solo $\left(\mathrm{m}^{3} \mathrm{~m}^{-3}\right)$ & & \\
$33 \mathrm{kPa}$ & 3,06 & 3,17 \\
1.500 $\mathrm{kPa}$ & 1,60 & 1,48 \\
$\mathrm{pH}$ (água) & 6,0 & 5,5 \\
\hline
\end{tabular}

Tabela 2. Atributos químicos do solo da área experimental

\begin{tabular}{lcc}
\hline \multicolumn{1}{c}{ Atributos químicos } & \multicolumn{2}{c}{ Camada (m) } \\
Complexo Sortivo $\left(\mathrm{cmol}_{\mathrm{c}} \mathrm{kg}^{-1}\right)$ & $0-0,20$ & $0,20-0,40$ \\
Cálcio & 1,4 & 1,4 \\
Magnésio & 1,3 & 1,4 \\
Sódio & 3 & 6 \\
Potássio & 0,09 & 0,14 \\
Hidrogênio + Alumínio & 1,32 & 1,48 \\
Alumínio & 0,15 & 0,15 \\
Soma de bases (S) & 5,79 & 8,94 \\
Capacidade de troca de cátions & 7,11 & 10,42 \\
Saturação de bases (\%) & 81,43 & 85,80 \\
Percentagem de sódio trocável (PST) & 1 & 1 \\
Carbono $\left(\mathrm{g} \mathrm{kg}^{-1}\right)$ & 5,04 & 3,72 \\
Nitrogênio $\left(\mathrm{g} \mathrm{kg}^{-1}\right)$ & 0,5 & 0,33 \\
Relação $\mathrm{C} / \mathrm{N}$ & 10 & 11 \\
Matéria orgânica $\left(\mathrm{g} \mathrm{kg}^{-1}\right)$ & 8,69 & 6,41 \\
Fósforo assimilável $\left(\mathrm{mg} \mathrm{kg}^{-1}\right)$ & 74 & 30 \\
\hline
\end{tabular}

O delineamento experimental adotado foi o de blocos ao acaso, com parcelas subsubdivididas (split split-plot) com dois tratamentos nas parcelas, cinco nas subparcelas e quatro na subsubparcelas, com quatro blocos. Em cada bloco, com área de $216 \mathrm{~m}^{2}(6 \times 36 \mathrm{~m})$, foram distribuídas aleatoriamente as duas parcelas, com área de $108 \mathrm{~m}^{2}$ (6 x $\left.18 \mathrm{~m}\right)$. Dentro das parcelas foram distribuídas, aleatoriamente, as subparcelas, constituídas por quatro fileiras de plantas de $6,00 \mathrm{~m}$ de comprimento, sendo que as duas linhas externas foram consideradas bordaduras, de modo a evitar eventuais influências entre os tratamentos e as duas fileiras internas, linhas úteis. As subsubparcelas, distribuídas aleatoriamente nas subparcelas, continham aproximadamente 30 plantas e foram distribuídas em quatro linhas de 1,50 m, obedecendo a um espaçamento regular de $0,20 \times 0,90 \mathrm{~m}$.

As parcelas se constituíram de dois tipos de água para irrigação (água de poço freático - AF e água de esgoto doméstico tratada - AE). Nas subparcelas, avaliou-se o efeito de cinco lâminas de irrigação baseadas na evaporação do tanque Classe " $\mathrm{A}$ " (ECA), e nas subsubparcelas foram testadas quatro doses de adubação nitrogenada.

As lâminas de irrigação corresponderama: L1, lâmina de irrigação referente a 25\% da ECA; L2, lâmina de irrigação referente 50\% da ECA; L3, lâmina de irrigação referente a 75\% da ECA; L4, lâmina de irrigação referente a 100\% da ECA e L5, lâmina de irrigação referente a $125 \%$. Em cada subparcela foi instalado, no início de cada linha lateral de irrigação, um registro de globo a fim de controlar a quantidade de água aplicada nas unidades experimentais, que variava conforme a modificação do tempo de irrigação devido à variação dos tratamentos.

O método de irrigação adotado foi o localizado, sendo dois sistemas (um para irrigação com água de esgoto doméstico tratada e o outro para água de poço freático), com gotejadores tipo autocompensantes, com vazão de $3,75 \mathrm{~L} \mathrm{~h}^{-1}$ a uma pressão de serviço de $100 \mathrm{kPa}$, espaçados $0,5 \mathrm{~m}$ na linha, sendo um gotejador por duas plantas.

As doses de nitrogênio corresponderam a: N1, $25 \mathrm{~kg} \mathrm{ha}^{-1}$ de N; N2, $50 \mathrm{~kg} \mathrm{ha}^{-1}$ de N; N3, $75 \mathrm{~kg} \mathrm{ha}^{-1}$ de N e N4, $100 \mathrm{~kg} \mathrm{ha}^{-1}$ de $\mathrm{N}$ utilizando-se, como fonte, a Uréia ( $45 \%$ de N) sendo que $40 \%$ das doses foram aplicados aos 15 dias após a emergência (DAE) e o restante aos 30 DAE.

A água de esgoto doméstico tratada utilizada na pesquisa foi tratada por sistema de lagoas de estabilização em série. As amostras das águas de esgoto doméstico tratada e do poço freático usadas na irrigação do girassol, foram analisadas no Laboratório de Engenharia Ambiental (LABOSAN) da Universidade Federal do Ceará, cujos resultados estão expostos na Tabela 3.

Tabela 3. Características químicas das águas utilizadas no experimento

\begin{tabular}{|c|c|c|}
\hline \multirow{2}{*}{ Parâmetro } & \multicolumn{2}{|c|}{ Tipos de água } \\
\hline & Poço & Esgoto \\
\hline $\mathrm{pH}$ & 6,0 & 7,8 \\
\hline $\mathrm{CE}\left(\mu \mathrm{S} \mathrm{cm}^{-1}\right)$ & 208 & 727 \\
\hline Sódio (mg L-1) & 19,2 & 53,7 \\
\hline Cálcio (mg L-1) & 16,0 & 45,4 \\
\hline Magnésio $\left(\mathrm{mg} \mathrm{L}^{-1}\right)$ & 16,2 & 28,0 \\
\hline Potássio $\left(\mathrm{mg} \mathrm{L}^{-1}\right)$ & 10,1 & 26,2 \\
\hline Alcalinidade $\left(\mathrm{mg} \mathrm{CaCO}_{3} \mathrm{~L}^{-1}\right)$ & 15,6 & 148,1 \\
\hline Cloretos $\left(\mathrm{mg} \mathrm{L}^{-1}\right)$ & 37,7 & 92,5 \\
\hline $\mathrm{DBO}\left(\mathrm{mg} \mathrm{O}_{2} \mathrm{~L}^{-1}\right)$ & 16,6 & 36,7 \\
\hline DQO não filtrada $\left(\mathrm{mg} \mathrm{O}_{2} \mathrm{~L}^{-1}\right)$ & 72,6 & 111,8 \\
\hline Sólido total $\left(\mathrm{mg} \mathrm{L}^{-1}\right)$ & 219,3 & 520,6 \\
\hline Sólidos solúveis total ( $\mathrm{mg} \mathrm{L}^{-1}$ ) & 6,8 & 15,2 \\
\hline Sólido dissolvidos total (mg L-1) & 214,8 & 547,5 \\
\hline Amônia (mg L-1) & 0,0 & 7,7 \\
\hline Fósforo $\left(\mathrm{mg} \mathrm{L}^{-1}\right)$ & 0,2 & 12.8 \\
\hline Coliformes total (NMP $100 \mathrm{~mL}^{-1}$ ) & $2,98 \mathrm{E}+02$ & $6,53 \mathrm{E}+02$ \\
\hline E. coli (ovos L-1) & $2,65 \mathrm{E}+01$ & $7,73 E+01$ \\
\hline Ovos de helmintos (UT) & 0,0 & 0,4 \\
\hline
\end{tabular}

A adubação mineral dos demais nutrientes baseou-se na análise química do solo e nas exigências nutricionais da cultura. Foi aplicado, em todas as unidades experimentais, o equivalente a $60 \mathrm{~kg} \mathrm{ha}^{-1}$ de $\mathrm{P}_{2} \mathrm{O}_{5}$ e $20 \mathrm{~kg} \mathrm{ha}^{-1}$ de $\mathrm{K}_{2} \mathrm{O}$, usando-se, como fontes, o fosfato de monoamônio (MAP) e o sulfato de potássio, respectivamente; já a adubação nitrogenada variou em função dos tratamentos descritos. Para suprir prováveis deficiências de micronutrientes, foram aplicados $12 \mathrm{~g}$ de FTE-BR $12(9 \%$ $\mathrm{Zn} ; 1,8 \% \mathrm{~B} ; 0,85 \% \mathrm{Cu} ; 3 \% \mathrm{Fe} ; 2,1 \% \mathrm{Mn}$ e $0,10 \% \mathrm{MO}$ ) por cova, na fundação, conforme recomendação da Universidade Federal do Ceará (UFC, 1993).

Em pleno florescimento da cultura foram avaliadas as seguintes variáveis: número de folhas, altura das plantas e o 
diâmetro do caule. Aos 90 dias após a semeadura (DAS) a irrigação foi suspensa utilizando-se o critério de que a cultura se encontrava no estádio de maturação fisiológica dos grãos, ou seja, eles já estavam com massa dura, caracterizando o alcance do estádio fenológico R9 (capítulo inclinado para baixo, com dorso e brácteas com coloração entre amarelo e castanho); já o diâmetro do capítulo foi medido aos 114 DAS, por ocasião da colheita.

Os dados das variáveis avaliadas foram submetidos à análise de variância pelo teste $\mathrm{Fa}$ a,05 e 0,10 de probabilidade. Verificado efeito significativo na análise de variância, os dados obtidos nos diferentes tratamentos de natureza qualitativa foram comparados através do teste de Tukey em nível de 0,05 e 0,10 de probabilidade e os de natureza quantitativa foram submetidos ao estudo de regressão, buscando-se ajustar equações com significados biológicos, sendo selecionados os modelos matemáticos que apresentaram melhores níveis de significância e maiores valores de coeficientes de determinação $\left(\mathrm{R}^{2}\right)$ utilizando-se, para isto, os softwares para análises estatísticas SAEG 9.0 UFV e Assistat 7.6 Beta.

\section{Resultados E Discussão}

O resumo das análises das variâncias para os dados da altura da planta (AP), diâmetro do caule (DC), número de folhas (NF) e diâmetro do capítulo (DCP) podem ser observados na Tabela 4. Pelos resultados apresentados verificou-se efeito significativo entre os tipos de água (AP - água de poço e AE água de esgoto doméstico tratada) em todas as variáveis analisadas. Ocorreu efeito significativo do tratamento lâmina de irrigação nas variáveis AP, DC e DCP; quanto às doses nitrogenadas, verificou-se efeito significativo apenas para variável DCP, constatando-se interação dupla significativa entre os fatores A x Le L x N na variável DCPe tripla A x L x N para as variáveis DC e DCP, revelando a dependência entre esses fatores.

Tabela 4. Resumo da análise da variância para os dados de altura das plantas (AP), diâmetro do caule (DC), número de folhas (NF) e diâmetro do capítulo (DCP) do girassol cultivado sob lâminas de irrigação com águas de poço e residuária tratada, sob diferentes doses de adubação nitrogenada

\begin{tabular}{lrlccc}
\hline \multirow{2}{*}{ FV } & \multirow{2}{*}{ GL } & \multicolumn{4}{c}{ Quadrados médios } \\
\cline { 3 - 7 } & & AP & DC & NF & DCP \\
Bloco & 3 & $9509,5 \mathrm{~ns}$ & $103,54^{*}$ & $66,69 \mathrm{~ns}$ & $0,264 \mathrm{~ns}$ \\
Trat. (A) & 1 & $5649,5^{*}$ & $150,02^{*}$ & $404,02^{*}$ & $81,283^{* *}$ \\
Resíduo A & 3 & 175,7 & 6,75 & 11,93 & 0,354 \\
Trat. (L) & 4 & $2197,90^{* *}$ & $32,16^{*}$ & $12,80 \mathrm{~ns}$ & $18,773^{* *}$ \\
Int. A x & 4 & $282,20 \mathrm{~ns}$ & $9,17 \mathrm{~ns}$ & $25,28 \mathrm{~ns}$ & $7,782^{* *}$ \\
Resíduo L & 24 & 337,94 & 8,23 & 11,32 & 0,227 \\
Trat. (N) & 3 & $225,244 \mathrm{~ns}$ & $6,97 \mathrm{~ns}$ & $6,22 \mathrm{~ns}$ & $9,451^{* *}$ \\
Int. A x N & 3 & $151,257 \mathrm{~ns}$ & $10,25 \mathrm{~ns}$ & $1,04 \mathrm{~ns}$ & 0,533 \\
Int. L x N & 12 & $56,479 \mathrm{~ns}$ & $2,46 \mathrm{~ns}$ & $8,05 \mathrm{~ns}$ & $2,112^{* *}$ \\
Int. A x L x N & 12 & $66,533 \mathrm{~ns}$ & $1,27 *$ & $6,71 \mathrm{~ns}$ & $1,367^{* *}$ \\
Resíduo N & 90 & 189,909 & 4,84 & 8,34 & 0,321 \\
\hline
\end{tabular}

* significativo $(P<0,05)$; ** significativo $(P<0,01)$; ns: não significativo

$\mathrm{FV}$ - fonte de variação; $\mathrm{GL}$ - grau de liberdade
As maiores médias da altura de planta $(112,41 \mathrm{~cm})$ foram obtidas quando se irrigou com água de reúso, quando comparadas às médias alcançadas com água de poço (100,52 $\mathrm{cm}$ ) (Tabela 5). Este melhor desempenho vegetativo se deve, provavelmente, aos nutrientes (macro e micronutrientes) dissolvidos na água de reúso; contudo, não se pode atribuir relação deste incremento com o nitrogênio dissolvido já que não foram observadas diferenças significativas $(\mathrm{p}<0,05)$ desta variável com o aumento das doses de nitrogênio.

Tabela 5. Altura média das plantas (AP), diâmetro do caule (DC) e número de folhas (NF) em função dos tipos de água de irrigação*

\begin{tabular}{cccc}
\hline Tipo de água & $\mathbf{A P}(\mathbf{c m})$ & $\mathbf{D C}(\mathbf{m m})$ & $\mathbf{N F}$ \\
Poço & $100,52 \mathrm{~b}$ & $13,30 \mathrm{~b}$ & $22,13 \mathrm{~b}$ \\
Esgoto & $112,41 \mathrm{a}$ & $15,23 \mathrm{a}$ & $25,31 \mathrm{a}$ \\
\hline * Médias seguidas de letras distintas, na coluna, diferem entre si a nível de & 0,05 de probabilidade
\end{tabular}

* Médias seguidas de letras distintas, na coluna, diferem entre si a nível de 0,05 de probabilidade pelo teste de Tukey

Os diâmetros médios dos caules obtidos foram de 13,30 e 15,23 mm para água de poço e de esgoto doméstico tratado, respectivamente (Tabela 5). A superioridade do diâmetro do caule quando irrigado com água de reúso, em comparação com o valor médio obtido com a irrigação com água de poço, pode estar associada aos nutrientes presentes na água de esgoto. Presume-se, no entanto, que assim como para a variável altura de planta, também não se pode inferir que tais respostas estejam associadas ao nitrogênio presente na água de reúso visto que não foi denotado efeito significativo do fator doses de nitrogênio para esta variável.

As maiores médias de número de folhas por planta com valor de aproximadamente 25 folhas, foram obtidas com o uso de água de esgoto na irrigação, diferenciando-se estatisticamente dos resultados obtidos com água de poço cujos valores médios se situaram em torno de 22 folhas planta $^{-1}$ (Tabela 5).

A maior altura da planta obtida com a irrigação com esgoto doméstico tratado condiz com os resultados obtidos por Sales (2008), ao avaliar a cultura da mamoneira sob dois tipos de água de irrigação (água de poço e água de esgoto doméstico tratada) e diferentes doses de boro e zinco e observar, também, efeito significativo da altura da mamoneira apenas para o fator tipo de água.

A ausência de efeitos significativos das doses nitrogenadas para a variável altura das plantas, corrobora com os resultados obtidos por Bruginski \& Pissaia (2002), que cultivaram o girassol sob crescentes doses nitrogenadas $(0,25,50,75,100 \mathrm{e}$ $\left.125 \mathrm{~kg} \mathrm{ha}^{-1}\right)$ e também não observaram diferença estatística para a variável, contrapondo o que foi constatado por Biscaro et al. (2008), que ainda avaliaram a altura das plantas do girassol e observaram diferenças significativas na variável em questão em função das doses de nitrogênio $\left(0,20,40\right.$ e $80 \mathrm{~kg} \mathrm{ha}^{-1}$ de N ).

$\mathrm{O}$ incremento significativo da altura das plantas em função do aumento da lâmina de irrigação corrobora com Silva et al. (2007), que, também avaliando o girassol sob diferentes níveis de irrigação (testemunha; 117,20; 350,84; 428,70 e 522, 14 mm) observaram efeito significativo do aumento da disponibilidade hídrica sobre a altura da planta, sendo 522,14 mm a lâmina que proporcionou a maior altura da planta $(1,51 \mathrm{~m})$. 
O aumento na altura da planta com o favorecimento hídrico foi semelhante para o tipo de água, sendo o modelo linear o que melhor se ajustou aos dados, com efeito significativo $(\mathrm{p}<0,05)$ e coeficientes de determinação de $\left(\mathrm{R}^{2}=0,8291\right)$ e $\left(\mathrm{R}^{2}=0,7024\right)$ para água de poço e esgoto tratada, respectivamente (Figura 1). Este aumento linear, também foi observado por Silva et al. (2007) e se deu em decorrência, sem dúvida, da tentativa da cultura de atingir sua máxima altura potencial de vez que neste trabalho o porte da planta se situou inferior aos valores médios sugeridos na literatura.

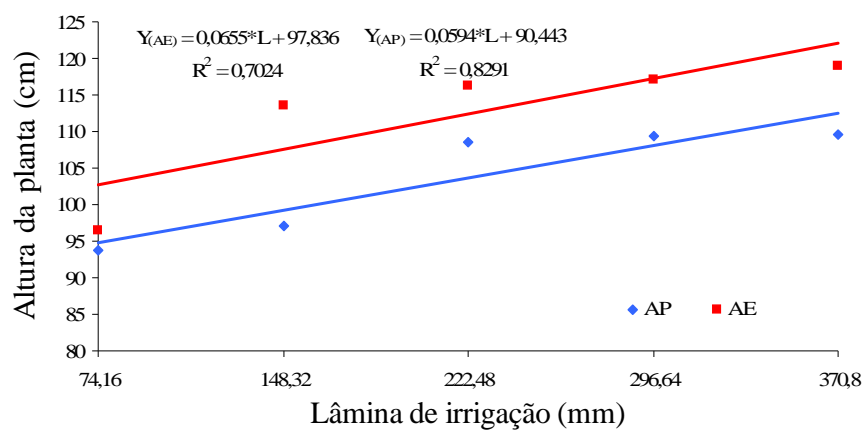

Figura 1. Altura da planta do girassol irrigada sob diferentes fontes hídricas, água de poço (AP) e água de esgoto doméstico tratada (AE) em função de diferentes lâminas de irrigação

Foram observados incrementos na altura das plantas de girassol de 17 e 23\%, entre o limite mínimo (L1 = 74,16 mm) e máximo (L5 = 370,80 mm) da lâmina de irrigação fornecida, para água de poço e esgoto, respectivamente, incrementos esses que se assemelham aos observados por Silva et al. (2007), que foram de $18,75 \%$ quando comparadas as alturas médias das plantas obtidas entre os tratamentos L3 $(522,14 \mathrm{~mm})$ e L0 $(117,20$ $\mathrm{mm})$.

O diâmetro do caule pouco se alterou com a disponibilidade hídrica do solo pois embora as lâminas de irrigação tenham influenciado esta variável, apenas entre os tratamentos L1 e L5 é que foi observada diferença estatisticamente significativa ( $\mathrm{p}$ $<0,05)$. Silva (2005), trabalhando com o girassol, também atribuiu à ausência de efeito significativo da disponibilidade hídrica do solo sobre o diâmetro do caule devido à sua própria estrutura, que funciona como verdadeiros drenos de água e nutrientes para as folhas e os capítulos.

Os dados de diâmetro do caule aumentaram de forma linear em função da disponibilidade hídrica com efeito significativo $(\mathrm{p}<0,05)$ e coeficientes de determinação de $\left(\mathrm{R}^{2}=0,8589\right)$ e $\left(\mathrm{R}^{2}=0,8059\right)$, para água de poço e esgoto, respectivamente (Figura 2). O incremento observado no diâmetro do caule foi de aproximadamente 22 e 19\%, para as águas de poço e esgoto, respectivamente.

Tais resultados contrapõem com os obtidos por Biscaro et al. (2008) que, também avaliando o girassol, cultivar H 358 da Dekalb, sob quatro níveis de adubação nitrogenada $(0,20,40$ e $80 \mathrm{~kg} \mathrm{ha}^{-1}$ ), observaram efeito significativo dos incrementos de nitrogênio sobre o diâmetro do caule. Ainda segundo os autores, o diâmetro máximo (18,4 mm) foi obtido com 47,8 $\mathrm{kg}$ de $\mathrm{N} \mathrm{ha}^{-1}$, valor este superior ao máximo observado no presente

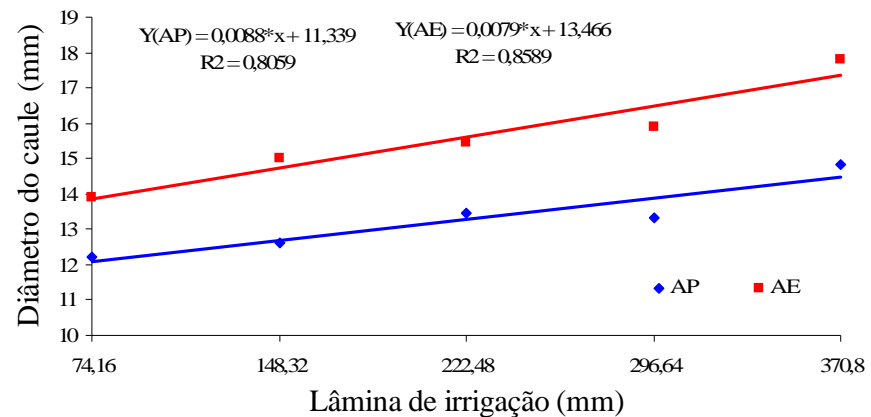

Figura 2. Diâmetro do caule do girassol irrigado sob diferentes fontes hídricas, água de poço (AP) e água de esgoto doméstico tratada ( $A E$ ) em função de diferentes lâminas de irrigação

trabalho, que foi de 14,13 e 15,46 mm para água de poço e esgoto, respectivamente. Referida diferença pode estar associada às particularidades genéticas fenotípicas inerentes à cultivar já que, no presente trabalho, utilizou-se a Multissol. Reforçando esta inferência, Smiderle et al. (2005) observaram, avaliando cultivares de girassol na savana de Roraima, diferença significativa entre os diâmetros dos caules das cultivares.

$\mathrm{O}$ efeito não significativo do número de folhas em função das doses de nitrogênio revela que, tal como os compostos nitrogenados, outros nutrientes presentes na água de reúso podem ter atuado em prol do melhor resultado do número de folhas.

O número médio de folhas por planta obtido quando se irrigou com água de poço, condiz com os observados por Afférri et al. (2008), que foram de 22 folhas para a cultivar Multissol, em Tocantins, revelando que os resultados obtidos com a água de poço podem não estar relacionados com uma eventual deficiência nutricional do girassol irrigado com este tipo de água mas, provavelmente, podem estar associados à própria qualidade intrínseca da água de reúso. Como relatado por Guidolin (2000), é imprescindível destacar o conteúdo dos elementos minerais presentes em efluentes urbanos brutos, sobretudo a presença de macronutrientes (N, P, K) e micronutrientes.

$\mathrm{O}$ efeito não significativo ( $\mathrm{p}<0,05)$, do número de folhas por planta em função das doses nitrogenadas, observado no presente trabalho, diverge dos resultados de Biscaro et al. (2008), ao registrarem efeito significativo de doses de nitrogênio no número de folhas por planta.

Assim como as doses de nitrogênio, as lâminas de irrigação não influenciaram significativamente no número de folhas por planta. Desta forma e já que não foi presenciada redução do número de folhas com a redução da disponibilidade hídrica, acredita-se que, provavelmente, pode ter ocorrido redução da área foliar, como estratégia de defesa adaptativa da planta para tolerar o déficit hídrico. De acordo com Nobre et al. (2010), a expansão foliar é muito sensível à deficiência hídrica sendo completamente inibida sob níveis moderados de estresse, o que afeta severamente as taxas fotossintéticas e, em consequência, a produção de fitomassa da parte aérea.

Outra provável justificativa para a ausência de influência das diferentes lâminas de irrigação na variável número de folhas se deve ao fato de que na cultura do girassol o número 
de folhas é definido muito cedo, entre 10 a 20 dias após a emergência, no período de diferenciação foliar (Merrien, 1992). Desta forma e como até os primeiros dez dias após emergência todos os tratamentos receberam a mesma lâmina de irrigação, $100 \%$ da ECA, a fim de uniformizar o estande, quando foram iniciadas as diferenciações dos tratamentos, é provável que o número de folhas já havia sido definido previamente.

A maior média de diâmetro do capítulo (DCP) de $16,05 \mathrm{~cm}$ foi obtida com uso de água de reúso, quando comparada ao diâmetro médio de 14,62 cm obtido com a água de poço, diferenciando-se estatisticamente $(\mathrm{p}<0,01)$ (Tabela 6). Deon et al. (2010) constataram, trabalhando com a cana-de-açúcar, maior rendimento para a cultura irrigada com água de reúso. Ainda segundos autores, a presença de nutrientes no efluente pode substituir parcialmente a adubação nitrogenada fato que, supostamente, pode ter influenciado e favorecido o maior diâmetro do capítulo obtido com água de reúso na presente pesquisa.

Os diâmetros médios gerais dos capítulos de 14,62 e 16,05 $\mathrm{cm}$ obtidos no presente trabalho para água de poço e água de esgoto, respectivamente, foram inferiores ao observado por Silva et al. (2011) de 18,06 para a cultivar Catissol 01; essa diferença se deve, provavelmente, em decorrência da componente genética já que no mesmo trabalho os autores observaram diâmetro médio de $16,88 \mathrm{~cm}$ para a cultivar Embrapa - V2000, denotando ainda diferenças significativas entre as cultivares, o que é condizente com as inferências de Castro \& Farias (2005), ao discorrerem que as variações no diâmetro do capítulo, são consequência das características intrínsecas a cada genótipo.

Avaliando o desempenho da variável diâmetro do capítulo em função da disponibilidade hídrica, a maior média de DCP para água de poço foi de $15,94 \mathrm{~cm}$, obtida com o tratamento L3 (222,48 mm), diferenciando-se estatisticamente dos demais tratamentos enquanto para água de esgoto as maiores médias do diâmetro do capítulo $(17,11 \mathrm{~cm})$ foram obtidas com L4 (296,64 $\mathrm{mm})$ não se diferenciando estatisticamente $(\mathrm{p}<0,05)$ da alcançada com o tratamento L3 $(222,48)$ de $16,72 \mathrm{~cm}$ (Tabela 5) esses valores são similares aos observados por Silva et al. (2007) e Silva et al. (2011) de 16,081 cm e 17,35 com as lâminas de irrigação correspondentes a 117,20 e 177,90 mm, respectivamente.

Embora Silva et al. (2011) tenham observado incrementos do diâmetro do capítulo com aumento da disponibilidade hídrica, até a lâmina de 355,80 mm, os autores não observaram diferença estatística entre os diâmetros dos capítulos, o que também foi observado por Silva et al. (2007) norteando que apenas a variação de um dos fatores de produção, como a água, pode não ser suficiente para a obtenção de uma variação expressiva na planta, já que outros fatores, como nutrientes, sanidade e clima, estão em equilíbrio.

No presente trabalho, o incremento médio do diâmetro do capítulo com o aumento da disponibilidade hídrica entre a maior e a menor lâmina de irrigação disponibilizada para a cultura, foi de $13 \%$ para água de poço, próximo aos observados por Silva et al. (2007) de 10\%; já para água de esgoto o incremento mensurado também entre as lâminas extremas, foi de aproximadamente $16 \%$. O maior incremento do DCP registrado para água de reúso, pode reforçar a hipótese de que a disponibilidade de nutrientes presentes na água de reúso favorece o desempenho da cultura do girassol.

Quanto à variação das doses de nitrogênio, as maiores médias de DCP foram de 15,38 cm e 16,57 cm com o N3 (75 $\mathrm{kg} \mathrm{ha}^{-1} \mathrm{de} \mathrm{N}$ ) para água de poço e esgoto, respectivamente (Tabela 6). Os valores médios de diâmetro do capítulo mesmo no tratamento submetido à menor dose de adubo nitrogenado $\left(\mathrm{N} 1=25 \mathrm{~kg} \mathrm{ha}^{-1}\right)$ para os dois tipos de água, foram superiores aos obtidos por Biscaro et al. (2008) quando, trabalhando com diferentes níveis de nitrogênio na cultura do girassol irrigada por gotejamento, obtiveram diâmetros médios máximos de 11,9 cm com 44,9 kg N ha-1 sendo registrado, a partir de então, decréscimo.

As médias de diâmetro dos capítulos obtidos para água de reúso em função das doses de nitrogênio sempre foram superiores aos diâmetros de capítulo obtidos para água de poço. Considerando os valores próximos do DCP de $15,38 \mathrm{~cm}$ e $15,75 \mathrm{~cm}$ obtidos com os tratamentos $\mathrm{N} 3=75 \mathrm{~kg} \mathrm{de} \mathrm{N} \mathrm{ha}^{-1} \mathrm{e}$

Tabela 6. Médias do desdobramento da interação tripla do diâmetro do capítulo (DCP) em função de dois tipos de água para irrigação (A), lâminas de água (L) e níveis de adubação nitrogenada (N )*

\begin{tabular}{|c|c|c|c|c|c|c|}
\hline \multirow{3}{*}{ Tipo de água } & \multirow{3}{*}{$\begin{array}{l}\text { Lâminas } \\
\text { de irrigação } \\
(\mathrm{mm})\end{array}$} & \multicolumn{4}{|c|}{ Níveis de nitrogênio $\left(\mathrm{kg} \mathrm{ha}^{-1}\right)$} & \multirow[b]{2}{*}{ Média } \\
\hline & & $\begin{array}{l}\text { N1 } \\
25\end{array}$ & $\begin{array}{l}\text { N2 } \\
50\end{array}$ & $\begin{array}{l}\text { N3 } \\
75\end{array}$ & $\begin{array}{c}\text { N4 } \\
100\end{array}$ & \\
\hline & & \multicolumn{5}{|c|}{ Diâmetro do capítulo } \\
\hline Poço & $\begin{array}{ll}\text { L1 } 74,16 \\
\text { L2 } 148,32 \\
\text { L3 } 222,48 \\
\text { L4 } 296,64 \\
\text { L5 } 370,80\end{array}$ & $\begin{array}{l}13,14 \\
15,03 \\
15,37 \\
13,34 \\
13,21 \\
\end{array}$ & $\begin{array}{l}14,36 \\
14,35 \\
15,52 \\
14,61 \\
13,12 \\
\end{array}$ & $\begin{array}{l}14,61 \\
15,19 \\
17,57 \\
15,15 \\
14,36 \\
\end{array}$ & $\begin{array}{l}14,28 \\
14,43 \\
15,31 \\
15,65 \\
14,00 \\
\end{array}$ & $\begin{array}{l}14,10 \mathrm{c} \\
14,75 \mathrm{~b} \\
15,94 \mathrm{a} \\
14,69 \mathrm{~b} \\
13,67 \mathrm{c}\end{array}$ \\
\hline & Média & $14,02 \mathrm{C}$ & $14,39 \mathrm{BC}$ & $15,38 \mathrm{~A}$ & $14,73 \mathrm{~B}$ & $14,62 \mathrm{~b}$ \\
\hline Esgoto & $\begin{array}{ll}\text { L1 } 74,16 \\
\text { L2 } 148,32 \\
\text { L3 } 222,48 \\
\text { L4 } 296,64 \\
\text { L5 } 370,80\end{array}$ & $\begin{array}{l}14,68 \\
15,77 \\
15,84 \\
17,34 \\
15,12\end{array}$ & $\begin{array}{l}14,83 \\
15,37 \\
16,21 \\
15,83 \\
16,31\end{array}$ & $\begin{array}{l}14,51 \\
15,27 \\
17,88 \\
17,48 \\
17,72\end{array}$ & $\begin{array}{l}14,85 \\
15,50 \\
16,94 \\
17,78 \\
15,88\end{array}$ & $\begin{array}{c}14,72 \mathrm{~d} \\
15,48 \mathrm{c} \\
16,72 \mathrm{ab} \\
17,11 \mathrm{a} \\
16,26 \mathrm{~b}\end{array}$ \\
\hline & Média & $15,75 \mathrm{~B}$ & $15,71 \mathrm{~B}$ & $16,57 \mathrm{~A}$ & $16,19 \mathrm{AB}$ & $16,05 \mathrm{a}$ \\
\hline
\end{tabular}

"Médias seguidas da mesma letra maiúscula nas linhas, minúscula nas colunas e minúscula em negrito na coluna não diferem estatisticamente pelo teste de Tukey a 0,05 de probabilidade 
$\mathrm{N} 1=25 \mathrm{~kg} \mathrm{ha}^{-1}$ de $\mathrm{N}$, irrigados com água de poço e reúso, respectivamente, pode-se constatar que, sem dúvida, o nitrogênio presente na água de reúso substituiu, em $50 \mathrm{~kg} \mathrm{ha}^{-1}$ de $\mathrm{N}$ o nitrogênio químico (Tabela 6) cuja diferença pode estar associada ao nitrogênio presente na água de reúso, fornecido em todos os eventos de irrigação. Segundo Zagonel \& Mundstock (1991), o nitrogênio atua na fase crítica de diferenciação floral e, em consequência, reflete no número de aquênios por capítulo e, por decorrência, também afeta o diâmetro do capítulo.

Segundo Qadir \& Oster (2004), a salinização ou a sodificação do solo pelo uso dos esgotos domésticos tratados na irrigação, normalmente não ocorre já que, comumente, as condutividades elétricas apresentadas por esses efluentes são inferiores a 1 $\mathrm{dS} \mathrm{m} \mathrm{m}^{-1}$, além disso, as próprias precipitações pluviométricas proporcionariam, em solos bem drenados, a diluição e lixiviação do sódio e dos demais sais acumulados no solo pelo uso de água de reúso. Desta forma, o uso de culturas toleráveis à salinidade da água de reúso pode ser um aliado adequado para a efetivação do uso racional da água de esgoto doméstico na agricultura.

A partir da análise de regressão dos dados de diâmetro do capítulo em função das lâminas de irrigação e das doses nitrogenadas, verificou-se que o modelo matemático que melhor se ajustou aos dados foi o modelo polinomial quadrático com efeito significativo $(\mathrm{p}<0,01)$ para o DCP do girassol irrigado com água de poço e esgoto, respectivamente (Tabela 7).

$\mathrm{Na}$ Figura 3A está representada a superfície de resposta do diâmetro do capítulo, para a água de poço, em função das lâminas de irrigação e das doses nitrogenadas. Observam-se incrementos do diâmetro do capítulo em função do aumento de ambos os fatores. De acordo com o modelo matemático selecionado, o diâmetro máximo do capítulo (ponto de máxima), seria de $15,9 \mathrm{~cm}$, obtido com a combinação dos tratamentos L3 (222,48 mm) e N3 (75 kg ha-1 de N), sendo este o recomendado para as condições em que o presente trabalho foi conduzido.

Para Souza et al. (2010), a variável diâmetro do capítulo é um dos componentes de produção mais sensíveis à presença de nitrogênio, respondendo significativamente com incrementos nesta variável, diante de pequenas doses, denotando que a adubação nitrogenada é de extrema importância para o girassol.
Entretanto, segundo Biscaro et al. (2008), para proporcionar bom crescimento no diâmetro do capítulo não é necessária uma alta quantidade de fertilizante nitrogenado, o que pode justificar a constatação de um ponto de máximo para as doses nitrogenadas, independente do tipo de água utilizado na irrigação.

Em diversos trabalhos nos quais se avaliou o desempenho das culturas em função das lâminas de irrigação e das doses de nitrogênio, têm sido observados efeitos quadráticos com o alcance de pontos de máximo, nas variáveis avaliadas em função do aumento dos fatores de produção lâmina e nitrogênio. Mousinho et al. (2003), observaram, avaliando o desempenho da melancia sob diferentes lâminas de irrigação e doses de nitrogênio, efeito quadrático da produção em função dos fatores de produção, o que também foi constatado por Silva et al. (2008) para a cultura da alface em função das lâminas de irrigação e doses de nitrogênio.

Biscaro et al. (2008) também observaram efeito quadrático do diâmetro do capitulo do girassol em função do aumento da doses de nitrogênio, obtendo diâmetro máximo estimado de

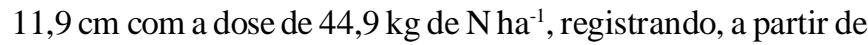
então, decréscimos do diâmetro do capítulo com aumento das doses de nitrogênio. A diferença entre os diâmetros máximos estimados em função da dose de nitrogênio ótima obtida no presente trabalho, quando comparada às obtidas por Biscaro et al. (2008) pode estar relacionada à disponibilidade hídrica, denotando a complementaridade desses fatores de produção para a produção do girassol.

Para água de reúso também foi observado incremento da variável DCP com o aumento dos fatores de produção nos quais a cultura foi submetida (Figura 3B). De acordo com o modelo matemático escolhido, o máximo diâmetro do capítulo, de $17,27 \mathrm{~cm}$ (ponto de máximo) seria obtido com a mesma dose de nitrogênio N3 $\left(75 \mathrm{~kg} \mathrm{ha}^{-1}\right)$; já quanto à disponibilidade hídrica, o diâmetro aumentou até a lâmina L4 (296,64 mm), decrescendo a partir de então.

Divergindo do modelo matemático (quadrático) obtido para o presente trabalho para explicar o comportamento do diâmetro do capítulo em face de crescentes doses de adubo nitrogenado nesta variável, Nobre et al. (2010) observaram, avaliando o desempenho do girassol em casa de vegetação sob lâminas de irrigação, incrementos lineares no diâmetro do capítulo com o

Tabela 7. Equações de regressão ajustadas e coeficientes de determinação $\left(R^{2}\right)$ para diâmetro do capítulo, em função de tipos de água, das lâminas de irrigação e doses de nitrogênio

\begin{tabular}{|c|c|c|c|c|c|c|}
\hline Tipo de água & Nome & Coeficiente & Desvio-padrão & Valor de T & Probab. & $\overline{R^{2}}$ \\
\hline Poço & $\begin{array}{l}\text { Constante } \\
\text { LAM } \\
\text { LAM }^{2} \\
\text { NIT } \\
\text { NIT }^{2} \\
\text { LAM*NIT }^{\text {N NIT }}\end{array}$ & $\begin{array}{r}\text { Mo } \\
10,630600 \\
0,032715 \\
-0,000078 \\
0,041980 \\
-0,000299 \\
0,000021\end{array}$ & $\begin{array}{c}\left.=a+b * X+c^{*}\right) \\
0,008175 \\
0,000016 \\
0,033019 \\
0,000244 \\
0,000052\end{array}$ & $\begin{array}{r}Z+e^{*} Z^{2}+f^{*} \\
\\
4,001698 \\
-4,724050 \\
1,271566 \\
-1,228200 \\
0,407423\end{array}$ & $\begin{array}{l}0,0007 \\
0,0002 \\
0,1121 \\
0,1198 \\
0,3449\end{array}$ & 0,69 \\
\hline Esgoto & $\begin{array}{l}\text { Constante } \\
\text { LAM } \\
\text { LAM }^{2} \\
\text { NIT } \\
\text { NIT }^{2} \\
\text { LAM*NIT }^{*} \text { NAM*NIT }\end{array}$ & $\begin{array}{r}\text { Modelo: } \\
14,431600 \\
0,017278 \\
-0,000053 \\
-0,066363 \\
0,000496 \\
0,000414 \\
-0,000003\end{array}$ & $\begin{array}{c}+b * X+c^{*} X^{2}+ \\
0,011869 \\
0,000018 \\
0,078760 \\
0,000620 \\
0,000320 \\
0,000003\end{array}$ & $\begin{array}{r}e^{*} Z^{2}+f^{*} X Z+ \\
1,455650 \\
-2,938770 \\
-0,842590 \\
0,800460 \\
1,294150 \\
-1,129010\end{array}$ & $\begin{array}{l}0,0846 \\
0,0058 \\
0,2073 \\
0,2189 \\
0,1091 \\
0,1396\end{array}$ & 0,69 \\
\hline
\end{tabular}


A.

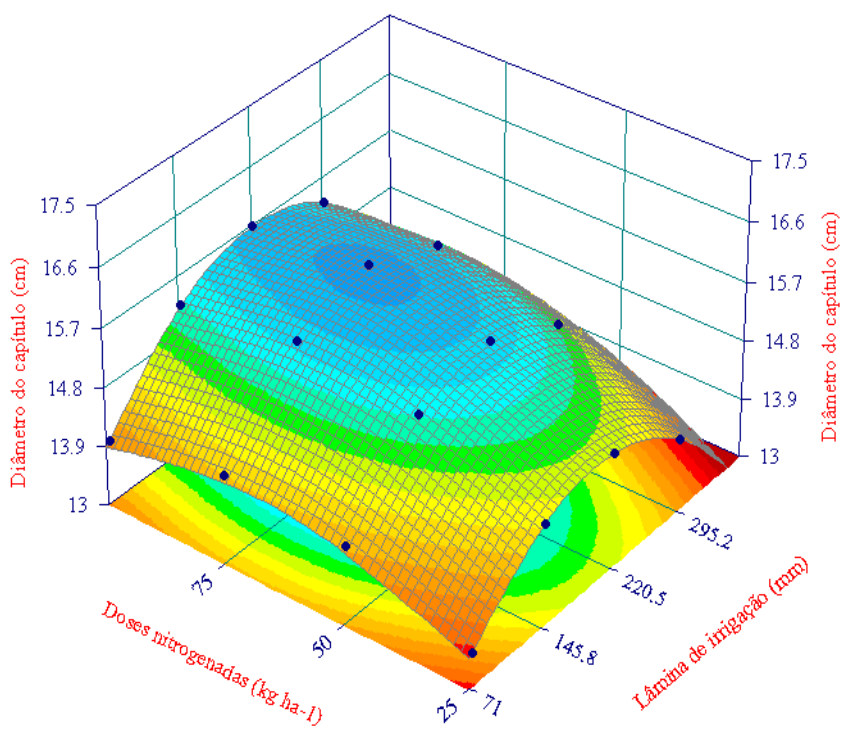

B.

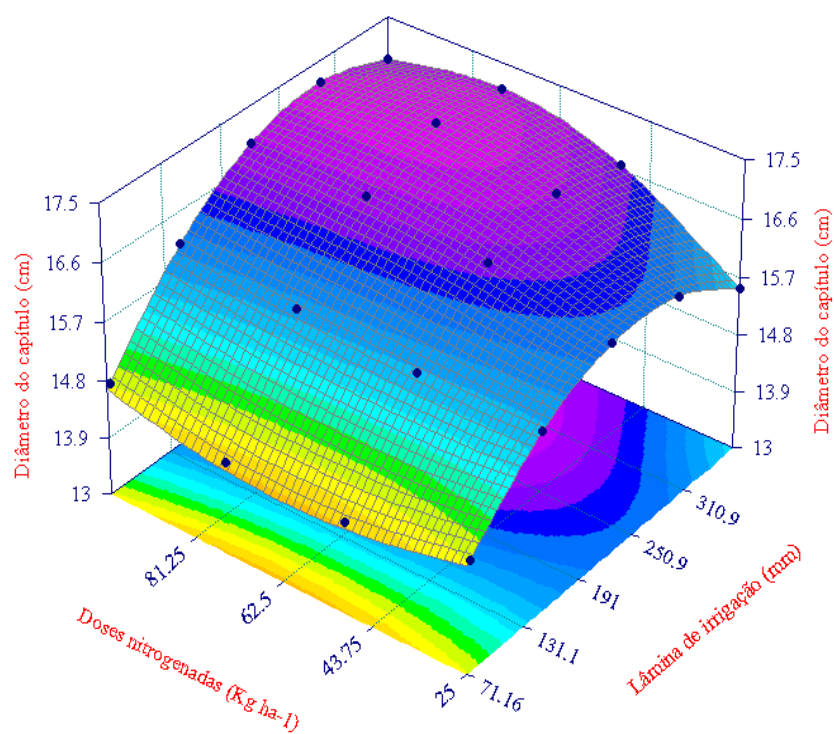

Figura 3. Superfície de resposta do diâmetro do capítulo do girassol irrigado com água de poço (A) e com água de esgoto doméstico tratada (B) em função das lâminas de irrigação e das doses nitrogenadas

favorecimento da disponibilidade hídrica (40, 60, 80, 100 e $120 \%$ do balanço hídrico). O diâmetro máximo do capítulo obtido na presente pesquisa $(17,27 \mathrm{~cm})$, se assemelhou ao obtido pelos referidos autores, com o tratamento equivalente a $60 \%$ da necessidade hídrica (aproximadamente 19,99 cm). Esta diferença pode estar atribuída às condições meteorológicas controladas dentro da casa de vegetação nas quais a pesquisa foi executada.

Os maiores diâmetros do capítulo foram estimados para água de reúso. Observando as Figuras $3 \mathrm{~A}$ e $3 \mathrm{~B}$, fixando a doses de nitrogênio em $25 \mathrm{~kg} \mathrm{ha}^{-1}$ (menor dose de nitrogênio) e variando o nível de irrigação, pode se observar o melhor desempenho do girassol irrigado com água de reúso na variável em questão, que se deve, provavelmente, ao favorecimento do nitrogênio presente na água de esgoto resultando em diâmetros de capítulos sempre maiores, quando comparados aos obtidos com água de poço nas mesmas lâminas de irrigação.

Um dos questionamentos em torno do uso da água de reúso na irrigação, diz respeito à condutividade elétrica, ao pH e à sodicidade da água, visto que, quando esses parâmetros químicos se encontram em concentrações prejudiciais às espécies vegetais, podem refletir no baixo desempenho da cultura, como constatado por Nobre et al. (2010) e o diâmetro do capítulo, por se mostrar altamente sensível, é a variável que melhor expressa os efeitos da salinidade da água sobre o girassol. Desta forma, e a partir dos bons resultados de diâmetro dos capítulos obtidos para o girassol irrigado com água de reúso, pode-se inferir que a água de esgoto doméstico tratado pode ser utilizada para irrigação da cultura do girassol.

\section{CONClusÕES}

1. Para o diâmetro do capítulo pode haver uma substituição parcial de aproximadamente $50 \mathrm{~kg} \mathrm{ha}^{-1}$ do nitrogênio comercial, pelo nitrogênio presente na água de reúso.
2. Para as variáveis altura da planta, diâmetro do caule e número de folhas, recomenda-se a lâmina de irrigação referente a $370,8 \mathrm{~mm}$ bem distribuída ao longo do ciclo da cultura, independente do tipo de água; já para a variável diâmetro do capítulo, recomenda-se a lâmina equivalente a 222,48 mm, independente do tipo de água utilizada na irrigação.

3. Os maiores diâmetros dos capítulos foram alcançados com a lâmina de irrigação referente a 222,48 mm e com a dose de adubação nitrogenada de $75 \mathrm{~kg} \mathrm{ha}^{-1}$, tanto para a irrigação com água de poço quanto para o esgoto doméstico tratado.

4. A água de esgoto doméstica tratada pode ser utilizada para o cultivo do girassol.

\section{AGRADECIMENTOS}

Os autores agradecem ao Conselho Nacional de Desenvolvimento Científico e Tecnológico (CNPq), à Fundação de Amparo à Pesquisa do Ceará (FUNCAP), pelo apoio financeiro a esta pesquisa e pela concessão das bolsas de estudos, e à Companhia de Água e Esgoto do Ceará - CAGECE pela infraestrutura disponibilizada.

\section{LITERATURA CITADA}

Afférri, F. S.; Brito, L. R.; Siebeneichler, S. C.; Peluzio, J. M.; Nascimento, L. C. do; Oliveira, T. C. de. Avaliação de cultivares de girassol, em diferentes épocas de semeadura, no sul do estado do Tocantins, safra 2005/2006. Amazônia: Ciência \& Desenvolvimento, v.4, p.79-87, 2008.

Barros V. da S.; Costa, R. N. T.; Aguiar, J. V. de. Função de produção da cultura do melão para níveis de água e adubação nitrogenada no Vale do Curu - CE. Irriga, v.7, p.98105, 2002. 
Bastos, R. K. X.; Bevilacqua, P. D.; Keller, R. Organismos patogênicos e efeitos na saúde humana. In: Desinfecção de efluentes sanitários. PROSAB 3. Riode Janeiro: ABES. p.27-88, 2003.

Biscaro, G. A.; Machado, J. R.; Tosta, M da S.; Mendonça, V.; Soratto, R. P.; Carvalho, L. A. de. Adubação nitrogenada em cobertura no girassol irrigado nas condições de CassilândiaMS. Ciência e Agrotecnologia, v.32, p.1366-1373, 2008.

Bruginski, D. H.; Pissaia, A. Cobertura nitrogenada em girassol sob plantio direto na palha: II - Morfologia da planta e partição de massa seca. Scientia Agraria, v.3, p.47-53, 2002.

Carelli; M. L. C.; Ungaro, M. R. G.; Fahl, J. I.; Novo, M. do C. de S. S. Níveis de nitrogênio, metabolismo, crescimento e produção de girassol. Revista Brasileira de Fisiologia Vegetal, v.8, p.123-130, 1996.

Castro, C.; Farias, J. R. B. Ecofisiologia do girassol. In: Leita, R. M. V. B. C.; Brighenti, A. M.; Castro, C. (ed). Girassol no Brasil. Londrina: EMBRAPA, 2005. p.163-218.

Cerqueira, L. L.; Fadigas, F. de S.; Pereira, F. A.; Gloaguen, T. V.; Costa, J. A. Desenvolvimento de Heliconia psittacorum e Gladiolus hortulanus irrigados com águas residuárias tratadas. Revista Brasileira de Engenharia Agrícola e Ambiental. v.12, p. 606-613, 2008.

Deon, M. D.; Gomes, T. M.; Melfi, A. J.; Montes, C. R.; Silva, E. da. Produtividade e qualidade da cana-de-açúcar irrigada com efluente de estação de tratamento de esgoto. Pesquisa Agropecuária Brasileira, v.45, p.1149-1156, 2010.

EMBRAPA - Empresa Brasileira de Pesquisa Agropecuária. Centro Nacional de Pesquisa de Solos. Sistema brasileiro de classificação de solos. 2.ed. Rio de Janeiro: EMBRAPA 2006. 306p.

Guidolin, J. C. Reúso de efluentes. Brasília: Secretaria de Recursos Hídricos, Ministério do Meio Ambiente, 2000. s.p.

Merrien, A. Physiologie du tournesol, Paris: CETION, 1992. $66 \mathrm{p}$.

Mousinho, F. E. P.; Costa, R. N. T.; Souza, F. de; Gomes Filho, R. R. Função de resposta da melancia à aplicação de água e nitrogênio para as condições edafoclimáticas de Fortaleza, CE. Irriga, v.8, p.264-272, 2003.

Nobre, R. G.; Gheyi, H. R.; Soares, F. A. L.; Andrade, L. O. de; Nascimento, E. C. S. Produção do girassol sob diferentes lâminas com efluentes domésticos e adubação orgânica. Revista Brasileira de Engenharia Agrícola e Ambiental, v.14, p.747-754, 2010.

Prado, R. de M.; Leal, R. M. Desordens nutricionais por deficiência em girassol var. Catissol 01. Pesquisa Agropecuária Tropical, v.36, p.187-193, 2006.

Qadir, M. Oster, J. D. Crop and irrigation management strategies for saline-sodic soils waters aimed at environmentally sustainable agriculture. Science of the Total Environment, v.323, p.1-19, 2004.
Ramos, J. M. O. Uso da água residuária na adubação: Vantagens e limitações. Revista Científica Eletrônica de Engenharia Florestal. v.10, p.1-20, 2007.

Sales, F. M. G. Resposta da mamona irrigada com esgoto sanitário tratado e poço freático as aplicações de zinco e boro em condições de baixa altitude. Fortaleza: UFC, 2008. 60 p. Dissertação Mestrado

Santos, M. da S.; Lima, V. L. A. de; Beltrão, N. E. de M.; Barros, H. M. M.; Sampaio, M. V.; Martins, E. S. C. da S. Produção de gergelim sob irrigação com água residuária tratada e adubação com torta de mamona. Tecnologia \& Ciência Agropecuária, v.4, p.31-35, 2010.

Santos, M. J. dos; Araújo, L. E.; Oliveira. E. M.; Silva, B. B. Seca, precipitação e captação de água de chuva no semiárido de Sergipe. Engenharia Ambiental, v.6, p.55-73, 2009.

Silva, A. R. A. da; Bezerra, F. M. L.; Sousa, C. C. M. de; Pereira Filho, J. V.; Freitas, C. A. S. de. Desempenho de cultivares de girassol sob diferentes lâminas de irrigação no Vale do Curu, CE. Revista Ciência Agronômica, v.42, p.57-64, 2011.

Silva, M. de L. O. e. Aplicações de lâminas de água e doses de boro na cultura do girassol. Lavras: UFLA, 2005. 115p. Tese Doutorado

Silva, M. L. O.; Faria, M. A.; Morais, A. R.; Andrade, G. P.; Lima, E. M. C. Crescimento e produtividade do girassol cultivado na entressafra com diferentes lâminas de água. Revista Brasileira de Engenharia Agrícola e Ambiental, v.11, p.482488, 2007.

Silva, P. A. M.; Pereira, G. M.; Reis, R. P.; Lima, L. A.; Taveira, J. H. da S. Função de resposta da alface americana aos níveis de água e adubação nitrogenada. Ciência e Agrotecnologia, v.32, p.1266-1271, 2008.

Smiderle, O. J.; Mourão Júnior, M.; Gianluppi, D. Avaliação de cultivares de girassol em savana de Roraima. Revista Acta Amazonica, v.35, p.331-36, 2005.

Sousa, J. T. de.; Ceballos, B. S. O. de; Henrique, I. N.; Dantas, J. P.; Lima, S. M. S. Reúso de água residuária na produção de pimentão (Capsicum annuum L.). Revista Brasileira de Engenharia Agrícola e Ambiental, v.10, p.89-96, 2006.

Souza, R. M. de; Nobre, R. G.; Gheyi, H. R.; Dias, N. Da S.; Soares, F. A. L. Utilização de água residuária e de adubação orgânica no cultivo do girassol. Revista Caatinga, v.23, p. 125-133, 2010.

UFC - Universidade Federal do Ceará. Recomendações de adubação e calagem para o estado do Ceará. Fortaleza: UFC, 1993. 194p.

Zagonel, J.; Mundstock, C. M. Doses e épocas de aplicação de nitrogênio em cobertura em duas cultivares de girassol. Pesquisa Agropecuária Brasileira, v.26, p.1487-1492, 1991. 